\title{
Brain and heart connections: The trigeminocardiac reflex!
}

\author{
Gyaninder P. Singh, Tumul Chowdhury'
}

\begin{abstract}
Trigeminocardiac reflex (TCR) is a well-established neurogenic reflex although its exact mechanism and clinical significance remain unclear.This reflex may be incited by stimulation of the trigeminal nerve anywhere along its course starting from the peripheral distribution to the central nucleus. It usually manifests as bradycardia, asystole, hypotension, apnoea and gastric hypermotility; though other clinical manifestation such as tachycardia and hypertension may also occur. Diving reflex (DR) shares many similarities with TCR in both clinical manifestation and mechanism of action and is often considered as a modified or subtype of TCR. DR is an important physiological adaptation to withstand hypoxia during apnoea in many animal species including humans and thus belongs to a group of oxygen-conserving reflexes. Although TCR is a physiological reflex having protective function, an exaggerated response may have fatal consequences. Surgeries or stimulation involving head, neck and face region (area supplied by trigeminal nerve) are particularly prone to provoke this reflex.Vigilant and continuous monitoring for early identification of warning signs and communication with surgeon to interrupt the stimulus immediately is enough to cease the reflex in most of the cases. However, failure to identify and treat in time may have deleterious consequences and thus TCR has gained much attention and awareness in recent years. Over the last two decades, our knowledge on TCR has expanded but we still remain far from complete elucidation of pathophysiology, mechanism and clinical significance of this unique 'brain and heart connection' calledTCR.
\end{abstract}

Key words: Bradycardia, hypotension, neurosurgery, trigeminocardiac reflex

\section{INTRODUCTION}

There exists a complex bidirectional interaction between the brain and heart. This has developed a new concept of field of neurocardiology. One of the unique examples of such connections is the trigeminocardiac reflex (TCR) that

Department of Neuroanaesthesiology and Critical Care, All India Institute of Medical Sciences, New Delhi, India, ${ }^{1}$ Department of Anaesthesiology and Perioperative Medicine, University of Manitoba, Winnipeg, MB, Canada

Address for correspondence:

Dr. Gyaninder P. Singh, Department of Neuroanaesthesiology and Critical Care, Room No. 711, $7^{\text {th }}$ Floor, Neurosciences Centre, All India Institute of Medical Sciences, New Delhi - 110 029, India.

E-mail: drsingh_gp@yahoo.co.in

\begin{tabular}{|l|l|}
\hline \multicolumn{2}{|c|}{ Access this article online } \\
\hline Quick Response Code: & Website: \\
\cline { 1 - 2 } & www.jnaccjournal.org \\
\cline { 2 - 2 } & \\
\hline & DOI: \\
\hline
\end{tabular}

is a well-known brainstem reflex and manifests during surgeries or stimuli involving the area of trigeminal sensory nerve innervations. It is considered as one of the most powerful autonomic reflexes in humans. This reflex is thoroughly investigated in various animal models and is usually considered as an oxygen-conserving reflex. Although literature highlights mainly the acute and mild nature of the TCR phenomenon, an exaggerated TCR response may be pathological and is often harmful or rarely fatal. Therefore, it is imperative to understand the mechanism, classification, manifestation, clinical significance and management of this reflex. In this review, we discuss in depth the present understanding and current status of our knowledge about this unique reflex.

This is an open access article distributed under the terms of the Creative Commons Attribution-NonCommercial-ShareAlike 3.0 License, which allows others to remix, tweak, and build upon the work non-commercially, as long as the author is credited and the new creations are licensed under the identical terms.

For reprints contact: reprints@medknow.com

How to cite this article: Singh GP, Chowdhury T. Brain and heart connections: The trigeminocardiac reflex!. J Neuroanaesthesiol Crit Care 2017;4:71-7. 


\section{DEFINITION AND HISTORICAL ASPECT}

The TCR is considered as a brainstem reflex which presents as sympathetic and parasympathetic imbalance. These, in turn, manifest as sudden onset of dysrhythmias (bradycardia and asystole), hypotension, apnoea and gastric hypermotility following the stimulation of the sensory branches of the trigeminal nerve along its course. The classic definition includes a decrease (heart rate and blood pressure) of $20 \%$ from the baseline values. This definition mainly includes clinically relevant episodes of the TCR phenomenon.

In the latter half of the $19^{\text {th }}$ century, Kratschmer's experiments on animals helped establish the mechanism and pathways of respiratory and cardiovascular reflexes upon stimulation of nose and larynx using natural stimuli such as cold air, tobacco smoke, carbon dioxide, ammonia and chloroform. ${ }^{[1-4]}$ He observed the reflex closure of the glottis and cardiovascular responses to stimulation of nasal and laryngeal mucosa. Kratschmer was first to describe cardiac arrhythmias on upper airway stimulation. ${ }^{[3]}$ In 1908, Dagnini independently described slowing of heart rate on application of pressure on the eyeball which was termed as the oculocardiac reflex. ${ }^{[5,6]}$ Kumada et al..$^{[7]}$ described a similar autonomic 'trigeminal depressor responses' after low-frequency electrical stimulation of the spinal trigeminal nucleus or peripheral trigeminal branches in anaesthetised or decerebrated rabbits indicating that both central and peripheral part of the trigeminal pathway can elicit the reflex. Interestingly, anaesthesiologists, Shelly and Church, coined the term 'Trigeminocardiac reflex' to describe the occurrence of bradycardia on stimulation of regions supplied by the branches of trigeminal nerve. ${ }^{[8]}$

\section{EPIDEMIOLOGY}

The TCR may be observed during various surgical procedures involving head, neck and face including skull base, ocular, maxillofacial surgery and dental. Depending on the type of the procedure, the incidence of the TCR varies from $5 \%$ to $90 \%$. Various factors are linked with the occurrence of TCR episodes and include higher resting vagal tone (younger age group), hypercarbia, hypoxaemia, light general anaesthesia and drugs (opioids, $\beta$-blockers and Ca-channel blockers). In addition, various types of stimuli including mechanical, thermal, electrical, infection and biochemical can provoke the TCR response. However, the mechanical stretch is considered to be the most powerful stimulus to incite the TCR phenomenon. Strikingly, Chowdhury and West have shown that even slight skin traction during the scalp closure can produce asystole. ${ }^{[9]}$ Similarly, chemical stimulation ${ }^{[10]}$ or inflammation ${ }^{[11]}$ may also predispose to TCR. Drugs (opioids, $\beta$-blockers and
Ca-channel blockers) cause decrease in heart rate and blood pressure as they inhibit the sympathetic nervous system, block sympathetic response of the heart or cause peripheral arterial vasodilatation and thereby predispose to TCR. ${ }^{[12,13]}$ A precedent transient ischaemic attack of $<6$ week has been found to be a predisposing factor of intraoperative TCR in subsequent surgery. ${ }^{[14]}$ All the above factors probably sensitise the trigeminal nerve, thereby making it more prone to trigger TCR following various stimuli. ${ }^{[10,15]}$

\section{CLINICAL SUBTYPES}

TCR has been described to occur during stimulation of any branch of the trigeminal nerve or the nerve itself along its course. Schaller et al. classified TCR into various subtypes based on the region of the trigeminal pathway stimulated. ${ }^{[16]}$ These subtypes include central, peripheral and ganglionic TCR. ${ }^{[12,15,17-19]}$

- Peripheral TCR results from stimulation of any peripheral branch of the trigeminal nerve, namely, ophthalmic, maxillary or mandibular nerve. Oculocardiac reflex is a common phenomenon during surgery of orbit around the eyeball due to stimulation of the ophthalmic branch. Stimulation of area innervated by maxillary or mandibular division of trigeminal nerve may elicit similar response called maxilla-mandibular cardiac reflex. These reflexes are a part of the broader term called TCR. Diving reflex (DR) which is a well-recognised and one of the most powerful autonomic reflexes is a peripheral type of TCR (modified TCR). This reflex is inherited from diving birds and amphibians and persists in human. ${ }^{[20-26]}$ Activities such as washing the face with cold water or plunging into cold water can provoke TCR (decrease heart rate) ${ }^{[2,28]}$ through the stimulation of trigeminal nerve branches over the face

- Central TCR is provoked by stimulation of the central (intracranial) part of the trigeminal nerve along its from gasserian ganglion to brainstem nuclei. This reflex is usually elicited during intracranial surgery near the brainstem and was first described by Schaller et al. in 1999 ${ }^{[29]}$

- Ganglionic TCR is another subtype of TCR which results from direct stimulation of gasserian ganglion. The clinical manifestations of gasserian ganglion stimulation are different from the other two subtypes and is considered as a separate subtype.

\section{PATHWAY}

Like other reflexes in the body, TCR also has an afferent and an efferent pathway. The receptors are located in the head, neck and face region innervated by the trigeminal nerve. Stimulation of these receptors by any stimuli (mechanical, chemical or electrical) or direct 
stimulation of trigeminal nerve or ganglion sends neuronal signals to the sensory nucleus of the trigeminal nerve. This forms the afferent path of the reflex. The sensory nucleus of trigeminal nerve is linked to reticular formation through polysynaptic connections which seems to be endogenously modulated by serotonergic (5-HT) and cholinergic receptors. ${ }^{[16,30,31]}$ The short internuncial fibres located in the reticular formation connect the afferent to the efferent pathway. The efferent pathway is primarily formed by neurons located in dorsal vagal nucleus and nucleus ambiguous, the fibres of which innervate the heart and other viscera through the vagus nerve [Figure 1]..$^{[32]}$ The central circuit of this reflex lies within the brainstem as animal studies have shown that the cardiac response can be seen even in decerebrate animals. ${ }^{[33]}$

However, the above pathway of the TCR does not always explain the different clinical manifestations seen with different clinical subtypes. In experimental models, other areas of the brainstem have also been found to be involved in TCR which include parabrachial nucleus, rostral ventrolateral medulla oblongata, dorsal medullary reticular field and paratrigeminal nucleus. ${ }^{[34-36]}$ There is also marked variation in the afferent pathway of the various subtypes of TCR leading to different reflex arcs and clinical manifestations. There are evidence that in peripheral TCR the impulses are relayed through the spinal nucleus of the trigeminal nerve to the Kolliker-Fuse nucleus, ${ }^{[37,38]}$ while in central TCR, the impulses are relayed through the nucleus of solitary tract to lateral parabrachial nucleus. ${ }^{[39]}$ In addition, it has been found that peripheral TCR activates both parasympathetic and sympathetic mediated response ${ }^{[40]}$ in contrast to the central TCR which predominantly activates the parasympathetic mediated vagal cardioinhibitory response. ${ }^{[41,42]}$ This further supports the difference in reflex arc in the two subtypes.

\section{CHRONIC TRIGEMINOCARDIAC REFLEX: A NEW ENTITY}

Most of the available literature on TCR describes the acute form of TCR either occurring during the surgery

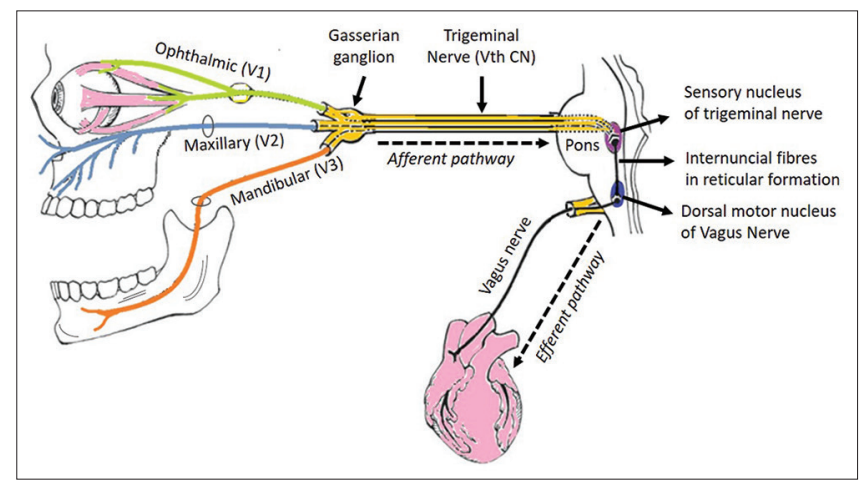

Figure 1: Trigeminocardiac reflex pathway or in immediate perioperative period. However, few reports describe late manifestation of TCR symptoms i.e., days, week, months or years after the injury. Recently, Chowdhury et al. first defined chronic TCR in such cases. ${ }^{[43,44]}$ The chronic TCR is defined as episodes persistent beyond $24 \mathrm{~h}$ of primary insult or intervention. In chronic TCR, the continuous/repetitive stimulation of trigeminal nerve can lead to vague and non-classical symptoms (nausea and dizziness) and there may be difference in reflex activity between the young and middle-aged population. ${ }^{[45]}$ Interestingly, in most of the chronic form of TCR, the ophthalmic branch was involved. ${ }^{[43,46,47]}$ In two cases, the TCR manifested several days after the clipping of intracranial aneurysm. ${ }^{[48]}$ Another patient reported to have symptoms of TCR one month after the orbital fracture which improved only after cessation of stimulus following repair of orbital floor. ${ }^{[43]}$ Yang and Oh described a case of chronic TCR, 40 years later caused due to stimulation by intraorbital foreign body. ${ }^{[46]}$ Matturri et al. have reported the death of an infant, hours after the submersion of face in water which triggered DR (modified TCR). ${ }^{[4]]}$ These reports highlight the importance of this hitherto underdiagnosed entity and have generated interest in research in this relatively newer concept of chronic TCR.

\section{CLINICAL PRESENTATIONS}

The TCR usually presents with sudden onset bradycardia or asystole, hypotension, apnoea and gastric hypermotility. However, the clinical presentations may be varied depending on the location of trigger point (clinical subtypes) [Table 1]. The peripheral subtypes of TCR manifest as bradycardia along with hypotension, normotension or even hypertension (DR). In contrast to this, the central TCR manifests as bradycardia and hypotension. The direct stimulation of trigeminal ganglion may manifest as any combination of brady- or tachycardia and hypo- or hypertension and was referred to as a different subtype by Chowdhury et al. known as ganglion Gasseri type. These varied presentations of the TCR are due to co-activation of parasympathetic and sympathetic nervous system. In the central TCR, the parasympathetic overactivity leads to bradycardia and hypotension. A strong sympathetic activity may even cause hypertension as in DR. The gasserian ganglion has mixed fibres including sensory (from V1, V2 and V3), motor (to V3) as well as sympathetic fibres from carotid plexus. This complexity of sympathetic and parasympathetic fibres in gasserian ganglion explains different types of presentation during ganglionic stimulation ranging from bradycardia and hypotension to tachycardia and hypertension depending on the fibres involved. ${ }^{[50-52]}$ 
Table 1: Clinical subtypes of trigeminocardiac reflex and their clinical manifestations

\begin{tabular}{llllll}
\hline Clinical subtype & Trigger point & Heart rate & Blood pressure & Respiration & Gastric motility \\
\hline Peripheral & $\begin{array}{l}\text { Stimulation of V1, } \\
\text { V2, V3 innervated } \\
\text { area }\end{array}$ & Bradycardia & $\begin{array}{l}\text { Hypotension or } \\
\text { normotension } \\
\text { (hypertension in } \\
\text { diving reflex) }\end{array}$ & Apnoea & Increased \\
Central & $\begin{array}{l}\text { Stimulation of } \\
\text { intracranial part of } \\
\text { trigeminal nerve }\end{array}$ & Bradycardia & Appotension & Apnoea & Increased \\
Ganglionic & $\begin{array}{l}\text { Direct stimulation of } \\
\text { gasserian ganglion }\end{array}$ & $\begin{array}{l}\text { Bradycardia } \\
\text { or tachycardia }\end{array}$ & $\begin{array}{l}\text { Hypotension or } \\
\text { hypertension }\end{array}$ & Apnoea & Increased \\
\hline
\end{tabular}

\section{TRIGEMINOCARDIAC REFLEX AS AN OXYGEN-CONSERVING REFLEX}

TCR (or DR) is a physiological reflex, which has been described to have a role in conserving body oxygen, thereby increasing survival under hypoxic/anoxic conditions. This reflex has been phylogenetically inherited from diving birds and amphibians. In response to diving (hypoxic environment), the DR is initiated due to stimulation of V1 (ophthalmic) division of trigeminal nerve which innervates the forehead, cornea and nasal mucosa. This results in bradycardia and apnoea (parasympathetic mediated) and peripheral vasoconstriction and increase in blood pressure (sympathetic mediated). Bradycardia decreases oxygen demand of the heart, and peripheral vasoconstriction limits the blood supply to peripheral non-vital organs while maintaining blood flow to important organs such as brain and heart. ${ }^{[22,53-55]}$ All these effects help reduce oxygen consumption during apnoea (hypoxic state) and thus have a direct oxygen-conserving effect. Several reports describe survival and complete recovery in humans following periods of prolonged (over an hour) submersion in water ${ }^{[56-59]}$ DR is thought to have an important role in survival of such individuals.

\section{CLINICAL SIGNIFICANCE}

TCR is physiological reflex which usually has a protective and purposeful function. However, sometimes, an exaggerated TCR response may lead to potentially harmful complications such as sudden asystole or apnoea. ${ }^{[13]}$ Due to these potentially life-threatening complications, TCR has gained enormous attention particularly during surgical procedures such as neurosurgical, neurointerventional, ocular, dental and oro-maxillo-facial surgeries. Common neurosurgical procedures where TCR has been reported include cerebellopontine angle (CPA) surgeries, trans-sphenoidal surgeries, microvascular decompression (MVD), aneurysmal clipping, percutaneous intervention procedures for trigeminal neuralgia and neurointerventional procedures.
Schaller et al. in 1999 first reported TCR (central TCR) during CPA surgery and the reported incidence was $11 \%$ with all cases experiencing sudden bradycardia and hypotension. ${ }^{[29]}$ In another study, Schaller et al. reported $18 \%$ incidence of TCR episodes in patients undergoing MVD for trigeminal neuralgia. ${ }^{[60]}$ During trans-sphenoidal pituitary surgery, the TCR has been reported to occur in $10 \%$ cases. ${ }^{[39]}$ In these cases, TCR occurred during lateral tumour dissection near cavernous sinus and was more common with tumour invading or compressing cavernous sinus, which suggests that TCR is elicited by V1 and V2 division of $\mathrm{V}^{\text {th }}$ cranial nerve passing through cavernous sinus. Although rare, Spiriev et al..$^{[6]]}$ suggested that the TCR episode can occur during aneurysm clipping. Importantly, various percutaneous procedures for trigeminal neuralgia (glycerol rhizolysis, balloon compression or radiofrequency ablation) are associated with occurrence of TCR. ${ }^{[52,62-67]}$ The incidence varies with the type of stimulus (chemical, mechanical compression or thermal) used during the procedure. Highest incidence is reported during percutaneous balloon compression. Besides these neurosurgical procedures, where TCR is more commonly reported, there are numerous case reports/series in literature which highlight the occurrence of TCR during other neurosurgical as well as neuroradiological ${ }^{[68,69]}$ procedures.

Another important clinical significant aspect of the TCR phenomenon is the effect of TCR on the functional outcome. In skull base tumour surgeries, the TCR episodes were linked with bad outcome (hearing loss, hormone normalisation, tinnitus, etc.). Chowdhury and Schaller recently reported the acute non-surgical cases related to the TCR and noted four cases with $100 \%$ mortality. ${ }^{[70]}$ In addition, the role of the TCR in various sleep disorders was also highlighted recently. ${ }^{[1,72]}$

\section{MANAGEMENT OF TRIGEMINOCARDIAC REFLEX}

Surgery in an area innervated by trigeminal nerve has a high risk of provoking TCR. Factors which are known to 
potentiate TCR such as hypoxia, hypercarbia, acidosis and light plane of anaesthesia should be corrected beforehand to prevent occurrence of this reflex. Infiltration of local anaesthetic or peripheral nerve block of the afferent nerve may be used as prophylaxis against peripheral TCR. ${ }^{[73,74]}$ The gentle and smooth manipulation during surgery reduces the risk of TCR. The surgeon should inform and alert the anaesthesiologist while approaching the trigeminal nerve or its branch. A close monitoring of the heart rate and blood pressure allows early detection of the event and immediate interruption of stimulus by the surgeon. This usually causes cessation of reflex and restores the heart rate and blood pressure to normal without use of drugs. ${ }^{[12]}$

However, if bradycardia and hypotension do not respond to interruption of stimuli, anticholinergic (atropine or glycopyrrolate) should be administered intravenously. ${ }^{[42]}$ Since TCR also has a sympathetic component and symptoms may occur due to decreased sympathetic tone rather than increased vagal stimulation, use of epinephrine rather than vagolytic agent will be efficacious in such cases. ${ }^{[12,75]}$ TCR refractory to all forms of treatment requiring cardiopulmonary resuscitation has been described. ${ }^{[13,75]}$

\section{FUTURE PROSPECTS}

The DR (a peripheral subtype of the TCR) is an oxygen-conserving reflex and has a protective role. Based on the existing knowledge, it seems that this reflex may have neuroprotective role by the activation of multilevel endogenous neuroprotective mechanisms. ${ }^{[76]}$ Similar to the DR, which protects an organism against hypoxia during diving, this reflex may also have protective action against various pathological conditions including brain ischaemia, stroke and traumatic brain injury. Future research to evaluate the TCR for prevention of brain hypoxia may provide a treatment option for ischaemic brain conditions such as for inducing tolerance to hypoxia during stroke and similar conditions. In addition, the recently recognised chronic form of the TCR needs further evaluation to understand this under-reported yet more debilitating form of TCR.

\section{CONCLUSION}

Since its first description, there has been a constant increase in our knowledge about this important neurogenic reflex - 'the brain and heart connection.' However, we still lag far behind in understanding the exact mechanism and clinical significance of TCR. There exist substantial gaps in our knowledge about this reflex. Further clinical and experimental research will help improve our knowledge and unwind the mysteries about this reflex and its role in other diseases.

\section{Financial support and sponsorship} Nil.

\section{Conflicts of interest}

There are no conflicts of interest.

\section{REFERENCES}

1. Kratschmer F. Uber reflexe von der nasenschleimhaut auf athmung und kreislauf. Sber Akad Wiss Wien 1870;62:147-70.

2. Kratschmer F. On reflexes from the nasal mucous membrane on respiration and circulation. Respir Physiol 2001;127:93-104.

3. Widdicombe J. Kratschmer and nasal reflexes. Respir Physiol 2001;127:89-91.

4. Widdicombe J. Reflexes from the lungs and airways: Historical perspective. J Appl Physiol 2006;101:628-34.

5. Ashner B. On a previously un-described reflection, of the eye on circulation and respiration. Disappearance of the radial pulse in pressure on the eye. Wien Klin Wochenschr 1908;21:1529-30.

6. Dagnini G. On a reflex provoked in some hemiplegics by stimulating the cornea and pressing the eyeball. Bull Sci Med 1908;8:380-1.

7. Kumada M, Dampney RA, Reis DJ. The trigeminal depressor response: A novel vasodepressor response originating from the trigeminal system. Brain Res 1977;119:305-26.

8. Shelly MP, Church JJ. Bradycardia and facial surgery [letter]. Anaesthesia 1988;43:422.

9. Chowdhury T, West M. Intraoperative asystole in a patient undergoing craniotomy under monitored anesthesia care: Is it TCR? J Neurosurg Anesthesiol 2013;25:92-3.

10. Spiriev T, Tzekov C, Kondoff S, Laleva L, Sandu N, Arasho B, et al. Trigemino-cardiac reflex during chronic subdural haematoma removal: Report of chemical initiation of dural sensitization. JRSM Short Rep 2011;2:27.

11. Spiriev T, Sandu N, Arasho B, Kondoff S, Tzekov C, Schaller B; Trigemino-Cardiac Reflex Examination Group (TCREG). A new predisposing factor for trigemino-cardiac reflex during subdural empyema drainage: A case report. J Med Case Rep 2010;4:391.

12. Arasho B, Sandu N, Spiriev T, Prabhakar H, Schaller B. Management of the trigeminocardiac reflex: Facts and own experience. Neurol India 2009;57:375-80.

13. Campbell R, Rodrigo D, Cheung L. Asystole and bradycardia during maxillofacial surgery. Anesth Prog 1994;41:13-6.

14. Nöthen C, Sandu N, Prabhakar H, Filis A, Arasho BD, Buchfelder $\mathrm{M}$, et al. Trigemino-cardiac reflex and antecedent transient ischemic attacks. Expert Rev Cardiovasc Ther 2010;8:509-12.

15. Chowdhury T, Mendelowith D, Golanov E, Spiriev T, Arasho B, Sandu N, et al. Trigeminocardiac reflex: The current clinical and physiological knowledge. J Neurosurg Anesthesiol 2015;27:136-47.

16. Meuwly C, Golanov E, Chowdhury T, Erne P, Schaller B. Trigeminal cardiac reflex: New thinking model about the definition based on a literature review. Medicine (Baltimore) 2015;94:e484.

17. Sandu N, Chowdhury T, Schaller BJ; Trigemino-Cardiac Reflex Examination Group (TCREG). How to apply case reports in clinical practice using surrogate models via example of the trigeminocardiac reflex. J Med Case Rep 2016;10:84.

18. Sandu N, Sadr-Eshkevari P, Schaller BJ; Trigemino-Cardiac Reflex Examination Group (TCREG). Usefulness of case reports to improve medical knowledge regarding trigemino-cardiac reflex in skull base surgery. J Med Case Rep 2011;5:149.

19. Sandu N, Schaller B. The trigemino-cardiac reflex: A view to the future. Arch Med Sci 2010;6:138-9. 
20. Schaller B, CorneliusJF, Sandu N, Ottaviani G, Perez-Pinzon MA. Oxygen-conserving reflexes of the brain: The current molecular knowledge. J Cell Mol Med 2009;13:644-7.

21. Schaller BJ, Sandu N, Cornelius JF, Filis A, Perez-Pinzon MA; Trigemino-Cardiac-Reflex-Examination-Group (T.C.R.E.G.). Oxygen-conserving implications of the trigemino-cardiac reflex in the brain: The molecular basis of neuroprotection? Mol Med 2009;15:125-6.

22. Alboni P, Alboni M, Gianfranchi L. Diving bradycardia: A mechanism of defence against hypoxic damage. J Cardiovasc Med (Hagerstown) 2011;12:422-7.

23. Sandu N, Cornelius J, Filis A, Nöthen C, Rasper J, Kulinsky VI, et al. Cerebral hemodynamic changes during the trigeminocardiac reflex: Description of a new animal model protocol. ScientificWorldJournal 2010;10:1416-23.

24. Sandu N, Spiriev T, Lemaitre F, Filis A, Schaller B; Trigemino-Cardiac-Reflex-Examination-Group (T.C.R.E.G.). New molecular knowledge towards the trigemino-cardiac reflex as a cerebral oxygen-conserving reflex. Scientific World Journal 2010;10:811-7.

25. Goksör E, Rosengren L, Wennergren G. Bradycardic response during submersion in infant swimming. Acta Paediatr 2002;91:307-12.

26. Foster GE, Sheel AW. The human diving response, its function, and its control. Scand J Med Sci Sports 2005;15:3-12.

27. Rossi L. Bulbo-spinal pathology in neurocardiac sudden death of adults: A pragmatic approach to a neglected problem. Int J Legal Med 1999;112:83-90.

28. Lobban $\mathrm{CD}$. The oxygen-conserving dive reflex re-examined as the principal contributory factor in sudden infant death. Med Hypotheses 1995;44:273-7.

29. Schaller B, Probst R, Strebel S, Gratzl O. Trigeminocardiac reflex during surgery in the cerebellopontine angle. J Neurosurg 1999;90:215-20.

30. Gorini C, Jameson HS, Mendelowitz D. Serotonergic modulation of the trigeminocardiac reflex neurotransmission to cardiac vagal neurons in the nucleus ambiguus. J Neurophysiol 2009;102:1443-50.

31. Gorini C, Philbin K, Bateman R, Mendelowitz D. Endogenous inhibition of the trigeminally evoked neurotransmission to cardiac vagal neurons by muscarinic acetylcholine receptors. J Neurophysiol 2010;104:1841-8.

32. Schaller B. Trigeminocardiac reflex. A clinical phenomenon or a new physiological entity? J Neurol 2004;251:658-65.

33. Elsner R, Gooden B. Diving and asphyxia. A comparative study of animals and man. Monogr Physiol Soc 1983;40:1-168.

34. Schaller BJ, Filis A, Buchfelder M. Cardiac autonomic control in neurosurgery: The example of trigemino-cardiac reflex. Arch Med Sci 2007;3:287-92.

35. Gorini C, Jameson H, Woerman AL, Perry DC, Mendelowitz D. Prenatal nicotine exposure enhances the trigeminocardiac reflex via serotonin receptor facilitation in brainstem pathways. J Appl Physiol 2013;115:415-21.

36. Ohshita N, Nakajo N, Takemura M. Characteristics of the trigeminal depressor response in cats. J Neurosci Res 2004;76:891-901.

37. Schaller BJ, Weigel D, Filis A, Buchfelder M. Trigemino-cardiac reflex during transsphenoidal surgery for pituitary adenomas: Methodological description of a prospective skull base study protocol. Brain Res 2007;1149:69-75.

38. Dutschmann M, Herbert H. The Kölliker-Fuse nucleus mediates the trigeminally induced apnoea in the rat. Neuroreport 1996;7:1432-6.

39. Schaller B. Trigemino-cardiac reflex during transsphenoidal surgery for pituitary adenomas. Clin Neurol Neurosurg 2005;107:468-74.

40. McCulloch PF, Faber KM, Panneton WM. Electrical stimulation of the anterior ethmoidal nerve produces the diving response. Brain Res 1999;830:24-31.

41. NalivaikoE, DePasqualeCG, BlessingWW.Electrocardiographic changes associated with the nasopharyngeal reflex in conscious rabbits: Vago-sympathetic co-activation. Auton Neurosci 2003;105:101-4.

42. Schaller B, Cornelius JF, Prabhakar H, Koerbel A, Gnanalingham K, Sandu N, et al. The trigemino-cardiac reflex: An update of the current knowledge. J Neurosurg Anesthesiol 2009;21:187-95.

43. Chowdhury T, Cappellani RB, Schaller B. Chronic trigemino-cardiac reflex in patient with orbital floor fracture: Role of surgery and first description. J Neurosurg Anesthesiol 2014;26:91-2.

44. Schaller BJ, Buchfelder M. Delayed trigeminocardiac reflex induced by an intraorbital foreign body. Ophthalmologica 2006;220:348.

45. Kuznetsova EA, Iakupov EZ. Evoked potentials and brainstem reflex activity in patients of young and middle age with chronic headache. Zh Nevrol Psikhiatr Im S S Korsakova 2011;111(8 Pt 1):27-30.

46. Yang HS, Oh DE. A case of delayed oculocardiac reflex induced by an intraorbital foreign body. Ophthal Plast Reconstr Surg 2011;27:e2-4.

47. Yilmaz T, Erol FS, Yakar H, Köhle U, Akbulut M, Faik Ozveren M. Delayed trigeminocardiac reflex induced by an intraorbital foreign body. Case report. Ophthalmologica 2006;220:65-8.

48. Spiriev T, Kondoff S, Schaller B; Trigemino-CardiacReflex-Examination-Group. Cardiovascular changes after subarachnoid hemorrhage initiated by the trigeminocardiac reflex-first description of a case series. J Neurosurg Anesthesiol 2011;23:379-80.

49. Matturri L, Ottaviani G, Lavezzi AM. Sudden infant death triggered by dive reflex. J Clin Pathol 2005;58:77-80.

50. Chen CY, Luo CF, Hsu YC, Chen JF, Day YJ. Comparison of the effects of atropine and labetalol on trigeminocardiac reflex-induced hemodynamic alterations during percutaneous microballoon compression of the trigeminal ganglion. Acta Anaesthesiol Taiwan 2012;50:153-8.

51. Reddy KR, Chandramouli BA, Rao GS. Cardiac asystole during radiofrequency lesioning of the trigeminal ganglion. J Neurosurg Anesthesiol 2006;18:163.

52. Meng Q, Zhang W, Yang Y, Zhou M, Li X. Cardiovascular responses during percutaneous radiofrequency thermocoagulation therapy in primary trigeminal neuralgia. J Neurosurg Anesthesiol 2008;20:131-5.

53. Landsberg PG. Bradycardia during human diving. S Afr Med J 1975;49:626-30.

54. de Bruijn R, Richardson M, Schagatay E. Oxygen-conserving effect of the diving response in the immersed human. Diving Hyperb Med 2009;39:193-9.

55. Leuenberger UA, Hardy JC, Herr MD, Gray KS, Sinoway LI. Hypoxia augments apnea-induced peripheral vasoconstriction in humans. J Appl Physiol 2001;90:1516-22.

56. Chochinov AH, Baydock BM, Bristow GK, Giesbrecht GG. Recovery of a 62-year-old man from prolonged cold water submersion. Ann Emerg Med 1998;31:127-31.

57. Huckabee HC, Craig PL, Williams JM. Near drowning in frigid water: A case study of a 31-year-old woman.J Int Neuropsychol Soc 1996;2:256-60.

58. Perk L, Borger van de Burg F, Berendsen HH, van't Wout JW. Full recovery after 45 min accidental submersion. Intensive Care Med 2002;28:524.

59. Schmidt U, Fritz KW, Kasperczyk W, Tscherne H. Successful resuscitation of a child with severe hypothermia after cardiac arrest of 88 minutes. Prehosp Disaster Med 1995;10:60-2.

60. Schaller B. Trigemino-cardiac reflex during microvascular 
trigeminal decompression in cases of trigeminal neuralgia. J Neurosurg Anesthesiol 2005;17:45-8.

61. Spiriev T, Kondoff S, Schaller B. Trigeminocardiac reflex during temporary clipping in aneurismal surgery: First description. J Neurosurg Anesthesiol 2011;23:271-2.

62. Lunsford LD, Apfelbaum RI. Choice of surgical therapeutic modalities for treatment of trigeminal neuralgia: Microvascular decompression, percutaneous retrogasserian thermal, or glycerol rhizotomy. Clin Neurosurg 1985;32:319-33.

63. Cha ST, Eby JB, Katzen JT, Shahinian HK. Trigeminocardiac reflex: A unique case of recurrent asystole during bilateral trigeminal sensory root rhizotomy. J Craniomaxillofac Surg 2002;30:108-11.

64. Mullan S, Lichtor T. Percutaneous microcompression of the trigeminal ganglion for trigeminal neuralgia. J Neurosurg 1983;59:1007-12.

65. Brown JA, Pilitsis JG. Percutaneous balloon compression for the treatment of trigeminal neuralgia: Results in 56 patients based on balloon compression pressure monitoring. Neurosurg Focus 2005;18:E10.

66. Chowdhury T, Cappellani RB, Schaller B; for Trigeminocardiac Reflex Examination Group (TCREG). Retrogasserian glycerol rhizolysis: First description of occurrence trigeminocardiac reflex. J Neurosurg Anesthesiol 2014;26:86-7.

67. Brown JA, Preul MC. Trigeminal depressor response during percutaneous microcompression of the trigeminal ganglion for trigeminal neuralgia. Neurosurgery 1988;23:745-8.
68. Tamura T, Rex DE, Marosfoi MG, Puri AS, Gounis MJ, Wakhloo AK. Trigeminocardiac reflex caused by selective angiography of the middle meningeal artery. BMJ Case Rep 2016;2016. pii: Bcr2016012517.

69. Ong CK, Ong MT, Le K, Power MA, Wang LL, Lam DV, et al. The trigeminocardiac reflex in Onyx embolisation of intracranial dural arteriovenous fistula. J Clin Neurosci 2010;17:1267-70.

70. Chowdhury T, Schaller B. The role of acute trigemino-cardiac reflex in unusual, non-surgical cases: A review. Front Neurol 2016;7:186.

71. Chowdhury T, Bindu B, Singh GP, Schaller B. Sleep disorders: Is the trigemino-cardiac reflex a missing link? Front Neurol 2017;8:63.

72. Singh GP, Chowdhury T, Bindu B, Schaller B. Sudden infant death syndrome-Role of trigeminocardiac reflex: A review. Front Neurol 2016;7:221.

73. Chigurupati K, Vemuri NN, Velivela SR, Mastan SS, Thotakura AK. Topical lidocaine to suppress trigemino-cardiac reflex. Br J Anaesth 2013;110:45.

74. Meuwly C, Chowdhury T, Schaller B. Topical lidocaine to suppress trigemino-cardiac reflex. Br J Anaesth 2013;111:302.

75. Prabhakar H, Ali Z, Rath GP. Trigemino-cardiac reflex may be refractory to conventional management in adults. Acta Neurochir (Wien) 2008;150:509-10.

76. Ramirez JM, Folkow LP, Blix AS. Hypoxia tolerance in mammals and birds: From the wilderness to the clinic. Annu Rev Physiol 2007;69:113-43. 